The International Journal of the First Year in Higher Education ISSN: 1838-2959

Volume 3, Issue 2, pp. 33-44

August 2012

\title{
Institution-wide peer mentoring: Benefits for mentors
}

\author{
Susan Beltman \\ Curtin University, Perth, Australia \\ Marcel Schaeben \\ RWTH-Aachen University, Aachen, Germany
}

\begin{abstract}
Extensive research has shown the benefits of mentoring, including peer mentoring, for higher education students, especially in their first year. However, few studies have focussed exclusively on the outcomes for the mentors themselves. This paper reports the findings of data gathered over three years about a university-wide peer mentoring program. Benefits identified by 858 mentors were coded inductively and four major categories emerged: altruistic, cognitive, social and personal growth. The findings have implications for the promotion of mentor programs to administrators and to prospective mentors. The study provides evidence that university-wide peer mentoring programs offer multiple positive outcomes for the mentors involved, and potentially for higher education institutions administering and supporting such programs.
\end{abstract}

\section{Please cite this article as:}

Beltman, S., \& Schaeben, M. (2012). Institution-wide peer mentoring: Benefits for mentors. The International Journal of the First Year in Higher Education, 3(2). 33-44. doi: 10.5204/intjfyhe.v3i2.124

This article has been peer reviewed and accepted for publication in Int J FYHE. Please see the Editorial Policies under the 'About' section of the Journal website for further information.

(C) Copyright of articles is retained by author/s. As an open access journal, articles are free to use, with proper attribution, in educational and other non-commercial settings. ISSN: 1838-2959 


\section{Introduction}

This paper reports on an institution-wide co-curricular approach to supporting first year students where all new students are offered a peer mentor who has already completed the first year of the same course. Supporting students in their first year in higher education has become even more of a priority with the Australian Government's commitment to expanding the university sector and increasing the number of graduates (Australian Government, 2009). The expansion focuses on attracting and retaining students from underrepresented groups who may "require higher levels of support to succeed, including financial assistance and greater academic support, mentoring and counselling services" (Australian Government, 2008, p. 27). While such supports may be provided by institutions "from above," this may be perceived as "imposed" and first year students may prefer to access networks that include "peers or family and intimates" (Morosanu, Handley, \& O'Donovan, 2010, p. 675). Interventions based on peers mentoring first year students partly address such concerns.

Peer mentoring programs have assisted first year students to successfully transition to university and be retained, to gain a sense of belonging, and to develop communication and organisational skills (Glaser, Hall \& Halperin, 2006). Programs with an academic focus have positively influenced achievement and approaches to learning (Dearlove, Farrell, Handa \& Pastore, 2007; Fox, Stevenson, Connelly, Duff \& Dunlop, 2010). There is evidence that mentor programs also benefit the university, coordinating staff and the mentors (Elliott, Beltman \& Lynch, 2011). Whilst studies have shown a variety of benefits, especially for mentees, there is limited research on the benefits for the mentors themselves. This paper aims to address this gap through examining a large scale, university-wide mentoring program.

Mentoring is a well-established, evidencebased social support strategy that can enhance academic, social, personal and career outcomes of recipients (MacCallum $\&$ Beltman, 2003). Those being mentored are typically called a protégé or mentee. A mentor, in the traditional sense, is "any caring, mature person who forms a one-onone relationship with someone in need" (Dondero, 1997, p. 882). Peer mentoring has been defined as "a helping relationship in which two individuals of similar age and/or experience come together, either informally or through formal mentoring schemes, in the pursuit of fulfilling some combination of functions" (Terrien \& Leonard, 2007, p. 150). According to Haggard, Dougherty, Turban and Wilbanks (2011) in their recent comprehensive review of literature, one of the core attributes of mentoring is that "mentoring requires a reciprocal relationship, involving mutuality of social exchange as opposed to a one-way relationship" (p. 292). Both mentor and mentee contribute to and benefit from the relationship.

Although mentoring is conceptualised as a mutually beneficial relationship involving reciprocity between the mentor and mentee, most research has focused on outcomes for mentees rather than for the mentors, leading to comparatively less understanding of mentors' experiences (Haggard et al., 2011), including outcomes for university student mentors (Hughes, Boyd, \& Dykstra, 2010). In their literature review, Ehrich, Hansford and Tennent (2004) found that "the most commonly cited mentor outcome was that of 
collegiality and networking" (p. 523). Studies have shown personal outcomes such as a sense of satisfaction and achievement through helping others (Shrestha, May, Edirisingha, Burke \& Linsey, 2009), and increased selfawareness and confidence (Heirdsfield, Walker, Walsh \& Wilss, 2008). Social outcomes have included an enhanced sense of connectedness (Terrion, Philion \& Leonard, 2007), and inter-cultural friendships (Devereux, 2004). Mentors have also reported an improvement of their professional and organisational skills that they have begun developing in their courses (Calder, 2004).

The aim of this study was to examine in more depth benefits for the mentors in an Australian university-wide peer mentoring program for first year students. Of the literature reviewed for this paper, those studies examining mentor benefits had small numbers of participants, with the exception of Glaser et al. (2006) with 164 participants. The present study aimed to expand the understanding of benefits perceived by mentors through the analysis of a large data base of evaluations. This study specifically focussed on the research question: What benefits do mentors of first year students report from their participation in this program?

\section{Methodology}

\section{Program structure}

The centrally organised mentoring program was introduced at Curtin University in 2008, and expanded to include every new undergraduate student (Curtin University, 2011a). Students who have successfully completed the first year of their course assist new students with their transition to university life, and link them to appropriate sources of support (Elliott et al., 2011). Students interested in being a mentor complete an application and send it to the local staff member who coordinates the program in their school or department. They state their beliefs about what they can contribute to, as well as gain from, the role of a mentor, and provide the name of an academic staff member as a referee (Curtin University, 2011b). Mentors are selected by the local mentor coordinator with one mentor for every 10 15 new students.

A centrally managed training and preparation program is run by an overall university Mentor Coordinator who then communicates with school or departmental local mentor coordinators. Mentors are required to participate in a one-day training workshop prior to Orientation Week (Curtin University, 2011c) and then to support students for their first semester. They are provided with information about the role of the mentor and the structure of the program, as well as insights into student development and transition. They are familiarised with the key sources of help for new students and learn how to communicate with the mentees in meetings as well as by email and mobile phone. Additionally, matters of cultural diversity and sensitivity are addressed. Mentors are provided with a Mentor Handbook and various printed and online resources (Curtin University, 2011d). They are required to complete an online evaluation in order to receive their final payment and certificate.

The Mentor Program is designed as an optout program. Every new student is assigned a mentor from the same course but can choose not to respond (Elliott et al., 2011). Mentors and mentees have an initial 
meeting during Orientation Week and are encouraged to schedule a second meeting in the first week of the semester. It is then left to individual groups whether to schedule further group or one-to-one meetings. Ongoing contact is continued throughout the semester, mainly via email. The Mentor Coordinator provides suggested email templates, and, along with the local staff mentor coordinators, provides ongoing support to the mentors. Mentors are formally recognised by the University through an honorarium payment, presentations, and comments on their academic transcript (Elliott et al., 2011).

\section{Participants}

The participants were 858 individual mentors (female: $n=599$, male: $n=259$ ) who gave consent to their data being used for research. Most $(n=708)$ were in a mentor role for one semester, 119 for two semesters, and some for three $(n=26)$ or four $(n=5)$ semesters. Table 1 indicates the number of mentors from each faculty over the three years of data available for this study. The total number is greater than 858 because of those mentors who undertook the role more than once. As the aim of the study was to gain an understanding of the nature of the benefits perceived by mentors, rather than provide specific information for the program itself, all available data were included from all semesters, all faculties and all mentoring occasions.

As seen in Table 1, the numbers of mentors varied across the semesters, depending on how many schools were involved in the program, and how many students were enrolled each semester. Second semester numbers were small, as fewer new students enrol mid-year and Semester 2 data were not available for all years. Overall, Health and Humanities were more highly represented than Business and Science and Engineering that joined the program later.

\begin{tabular}{|c|c|c|c|c|c|c|}
\hline Faculty & 2009 Sem 1 & $\begin{array}{r}2010 \text { Sem } \\
1\end{array}$ & $\begin{array}{r}2010 \text { Sem } \\
2\end{array}$ & $\begin{array}{r}2011 \text { Sem } \\
1\end{array}$ & Missing & Total (\%) \\
\hline Humanities & 138 & 114 & 21 & 87 & & 360 (34.48) \\
\hline Health & 78 & 116 & 19 & 120 & & $333(31.90)$ \\
\hline Business & 0 & 128 & 30 & 70 & & $228(21.84)$ \\
\hline $\begin{array}{l}\text { Science and } \\
\text { Engineering }\end{array}$ & 18 & 34 & 7 & 58 & & 117 (11.21) \\
\hline Missing data & & & & & 6 & $6(0.57)$ \\
\hline Totals & 234 & 392 & 77 & 335 & 6 & $1,044(100)$ \\
\hline
\end{tabular}




\section{Surveys}

The program coordinators centrally collect evaluation data every semester, including a compulsory mentor survey. A number of questions are asked in the evaluation, such as views of training, of communication with school mentor coordinators, of frustrations with the program, and of perceived benefits for the mentors themselves. Room is provided for additional comments. Mentor response rates ranged from $88.5 \%$ to $94.9 \%$.

In 2009 and 2010, mentors were specifically asked: Comment about the things you have enjoyed or found beneficial about being a student mentor. What have you gained and/or found really satisfying from this role? In 2011, only one question was used, asking for general comments about the program. Evaluation data from Semester 1 2009, Semesters 1 and 2 2010, and Semester 12011 were aggregated in order to gain a broader understanding of positive outcomes perceived by the mentors for themselves.

\section{Data analysis}

Answers containing multiple benefits were split and coded separately so the number of benefits $(1,285$ separate benefits coded) was greater than participants. Several samples of 50 responses were independently coded by two researchers using an inductive-deductive approach. First, each researcher divided a set of 50 responses into groups of similar benefits. Each researcher assigned descriptions to the groups, closely resembling the language used by participants. Then, the groups and their descriptions were compared and the categories refined and adjusted until agreement between the researchers was reached. To check these categories, one researcher coded another set of 50 responses. Further discussion and refinement occurred until agreement occurred and a detailed coding system was developed.

To verify the coding system, a single new set of 50 responses was assigned to both researchers who coded them individually then met to compare and discuss the coding. The iterative process of comparing and refining categories continued once more with a further set of 50 responses until a detailed coding system was developed, and included sub-categories within major categories (see Table 2). Krippendorff's Alpha coefficient (Hayes, 2005; Hayes \& Krippendorff, 2007) was used to determine inter-rater reliability. As this was satisfactory (Krippendorff's Alpha $>0.7$ ), one researcher coded the remaining responses.

\section{Results}

The majority of the 1285 responses fitted into four major categories: Altruistic (47.0\% of all benefits), Cognitive (17.8\%), Social (14.7\%) and Personal Growth (14.0\%). Within each major category, there were several sub-categories. Table $2 \mathrm{a}$ and Table $2 b$ indicate the frequencies and percentages (within each major category) of all sub-categories in the four major categories. The most frequent major category was Altruistic $(47.0 \%$ of all responses) which included responses that mentioned enjoyment and satisfaction from helping people. An example of a response was one female art student who wrote in 2009: It is genuinely rewarding to know that someone feels more able to appreciate an experience because of the support you have offered. Similarly, a female 


\begin{tabular}{|c|c|c|c|}
\hline \multicolumn{4}{|c|}{ Table 2a: Frequencies of major categories and sub-categories } \\
\hline $\begin{array}{l}\text { Major } \\
\text { Category }\end{array}$ & Sub-category & Frequency & $\begin{array}{l}\text { Percent } \\
\text { within each } \\
\text { category }\end{array}$ \\
\hline \multirow[t]{6}{*}{ Social } & Enjoyed getting to know/interacting with new students & 119 & 63.0 \\
\hline & $\begin{array}{l}\text { Developed friendship/stayed in touch/rewarding } \\
\text { relationship with mentees }\end{array}$ & 37 & 19.6 \\
\hline & Networking with other mentors & 27 & 14.3 \\
\hline & Social benefits in general & 3 & 1.6 \\
\hline & Enjoyed coordinating between mentees and staff & 3 & 1.6 \\
\hline & Total & 189 & 100.0 \\
\hline \multirow[t]{9}{*}{$\begin{array}{l}\text { Personal } \\
\text { Growth }\end{array}$} & $\begin{array}{l}\text { Would have liked a mentor themselves / reflected on own } \\
\text { experiences as new uni student }\end{array}$ & 54 & 30.0 \\
\hline & Developed confidence & 33 & 18.3 \\
\hline & $\begin{array}{l}\text { Developed empathy with students/aware of/ appreciate their } \\
\text { issues/inspired by mentees/"eye opener" }\end{array}$ & 29 & 16.1 \\
\hline & Sense of involvement with / contribution to university & 27 & 15.0 \\
\hline & Being role model / inspiring others & 14 & 7.8 \\
\hline & Pride / sense of achievement & 11 & 6.1 \\
\hline & Sense of responsibility & 8 & 4.4 \\
\hline & Personal growth in general & 4 & 2.2 \\
\hline & Total & 180 & 100.0 \\
\hline
\end{tabular}

business student in 2010 said: I feel really happy knowing I'm making at least a small impact on someone's integration into uni.

The second most frequent group of responses, Cognitive $(17.8 \%$ of all responses), included acquiring new skills or information (e.g. developing communication skills; learning about resources of the university), or gaining experience in skills the mentors already had, thus enhancing them (e.g. leadership experience). In 2011 a female pharmacy student wrote: The mentor program has helped define myself as a leader, and I look forward to taking part in many other leadership and mentoring roles in my immediate future and during my career. A female media student in 2009 commented: There were a lot of things about the university and services that I wasn't aware of until I did the training for the mentoring program.

The third most frequent category was Social $(14.7 \%$ of all responses). Many participants mentioned social benefits such as interacting with new students or developing friendships with them. For example, a male physiotherapy student in 2010 wrote: It has been extremely fun just to socialise with the mentees. In 2009, a female education student wrote: I enjoyed meeting the first years - it is always good to meet new people. Networking with fellow mentors was also mentioned. A female 


\begin{tabular}{|c|c|c|c|}
\hline \multicolumn{4}{|c|}{ Table 2b: Frequencies of major categories and sub-categories } \\
\hline $\begin{array}{l}\text { Major } \\
\text { Category }\end{array}$ & Sub-category & Frequency & $\begin{array}{l}\text { Percent } \\
\text { within each } \\
\text { category }\end{array}$ \\
\hline \multirow[t]{7}{*}{ Altruistic } & $\begin{array}{l}\text { Enjoyed / satisfied as helped new students with } \\
\text { difficulties / problems / settling in }\end{array}$ & 316 & 52.3 \\
\hline & Passing on own experience and knowledge & 130 & 21.5 \\
\hline & $\begin{array}{l}\text { Enjoyed / appreciated positive feedback / response from } \\
\text { mentees }\end{array}$ & 85 & 14.1 \\
\hline & Making a difference / having an impact & 37 & 6.1 \\
\hline & Being available if needed & 33 & 5.5 \\
\hline & Pride in achievements of mentees & 3 & .5 \\
\hline & Total & 604 & 100.0 \\
\hline \multirow[t]{10}{*}{ Cognitive } & Leadership skills / experience & 84 & 36.7 \\
\hline & Communicaiton skills & 32 & 14.0 \\
\hline & Learnt about university resources & 29 & 12.7 \\
\hline & Helpful training & 21 & 9.2 \\
\hline & Organisational skills / experience & 21 & 9.2 \\
\hline & Professional development / career development / CV material & 20 & 8.7 \\
\hline & Learnt skills / gained knowledge in general & 9 & 3.9 \\
\hline & Interpersonal skills & 8 & 3.5 \\
\hline & Social skills & 5 & 2.2 \\
\hline & Total & 229 & 100.0 \\
\hline \multirow[t]{5}{*}{ Other } & Other & 50 & 60.2 \\
\hline & No response from mentees & 22 & 26.5 \\
\hline & No benefits & 11 & 13.3 \\
\hline & Total & 83 & 100.0 \\
\hline & Overall Total Benefits & 1285 & \\
\hline
\end{tabular}

architecture student said in 2009 she benefitted from meeting the other student mentors.

Finally, the fourth major group of benefits was Personal Growth $(14.0 \%$ of all responses). Responses related to self and personal development (e.g. developing confidence; gaining a sense of pride or responsibility; developing empathy). The most frequent sub-category reflected developing self-awareness where mentors reflected on their own experiences and growth. For example, a female occupational therapy student wrote in 2009: It enabled me to reflect on my own learning experiences, as it was very similar to some of the mentees' situations I've encountered - it was a bit like deja vu at times. Several reported that they would have liked a 
mentor in their first year when feeling confused such as the female accounting student in 2010 who said: If I could have asked another student, I think $i$ [sic] would have had a better first year at uni. An interesting comment made by several students was that, through getting to know and assisting first years, they could see their own growth.

It has made me think back to when I first started uni and the emotions that I felt back them, as well as my journey from them to now. [female education student, 2010]

The process really reminds you of how overwhelming uni can be at first and that by 3 rd year you have come a long way. [male public health student, 2010]

Also in the category of Personal Growth, mentors reported that they had gained confidence through the activities of the program such as the male art student who wrote in 2009: I found that my confidence in contacting people and communicating via email has increased greatly. Responses not fitting any of the major categories were categorised as Other.

\section{Discussion}

\section{Summary of findings}

In summary, mentors primarily reported a sense of achievement and satisfaction in their role of assisting new students. They also developed skills for their personal and professional lives, and appreciated the opportunity for leadership experience and development. In a practical sense, they learnt about resources and services available in their university that they were not aware of before. Mentors also enjoyed the opportunity to get to know and interact with new students in their field, which built rapport between students from different years. Some stayed in touch with their mentees, and some developed friendships. Mentors also got to know other mentors through the training and the meetings with the staff coordinator, expanding their social networks. The experience of mentoring contributed to the mentors' emotional and personal growth as they gained confidence, taking pride in their role as a mentor and being a role model for their mentees. Many mentors reflected on their own experiences as a first year and subsequent progress. By getting insight into their mentees' issues, mentors developed empathy with their mentees and were made aware of the problems of first year students from different backgrounds.

\section{Relation of findings to previous research}

Overall, the findings from this large sample of mentor responses were consistent with benefits reported in previous studies. By far the most common benefits reported by mentors in this study were altruistic. Mentors enjoyed passing on their knowledge and experience to new students and appreciated positive feedback from mentees. Shrestha et al. (2009) also found such benefits to be important. According to Heirdsfield et al. (2008), mentors felt rewarded as "mentees often expressed gratitude for their mentor's support" (p. 117).

The importance of cognitive benefits in this study is also consistent with the literature. For example, Calder (2004) said that mentors "appear to relish the opportunity to demonstrate or refine the skills that they have learnt in other aspects of their 
university study (p. 12). In their review of mentoring in education and other professions, Ehrich et al. (2004) indicated that mentors experienced an increase in their knowledge about their own university or institution. Drew, Pike, Pooley, Young, and Breen (2000) found that psychology student mentors gained information and knowledge about their university and specific school.

Social outcomes were the third most frequently reported benefit by mentors in this study. Ehrich et al. (2004) found networking and collegiality the most common outcomes for mentors. Other studies have also reported such benefits. For example, acting as a mentor provided "increased opportunities for socialising" (Shrestha et al., 2009, p. 119). Terrion et al. (2007) reported "increased social capital" (p. 53) as an important outcome for mentors, being defined as "the sense of connectedness with others in the university (other students, professors, other mentors, and resource people)" (p. 50). Building friendships and lasting relationships with people they would not have met otherwise was also an important part of the mentors' experience in some programs where some students formed "their first real intercultural friendship" (Devereux, 2004, p.6). Mentor programs appear to enhance connections between students and different aspects of their university in various ways.

The final major category of benefits for mentors in this study was Personal Growth. These outcomes revealed enhanced selfawareness and self-development, reflecting the reciprocal nature of the mentoring relationship as suggested by Haggard et al. (2011). The mentoring literature reports gains in self-esteem and confidence of mentors. For example, Shrestha et al.
(2009) found that mentors reflected upon and so were able to improve their performance, and Heirdsfield et al. (2008) that mentors reported greater selfawareness. An interesting finding in the present study was that mentors, through their interaction with new students, could not only recall how they themselves had felt as new students, but also could see how far they had progressed over time. Such findings offer universities validation for the strategy of supporting first years as well as evidence for ongoing student development through their courses. Mentors working in different contexts have reported that reflection on this role leads to new understandings of the self and one's profession (Ehrich et al., 2004; Gilles \& Wilson, 2004).

\section{Limitations of the study}

There were some limitations to the study and these also provide direction for future research. The evaluations completed by the mentors were developed by the program coordinators. In response to university priorities, the actual questions were not identical across year groups. The 2011 group was not specifically asked about benefits and perhaps they would have reported differently had they been. For 2012, the more specific questions will be reintroduced to facilitate future comparisons. The analyses reported in this paper are quite global. Differences between years, genders or faculties are not examined. This is partially due to the fact that over the period of data collection, different faculties have taken up the program, resulting in different amounts of data from different faculties. There may well be differences between genders or faculties and this is an area for further investigation. Although the program is run 
centrally, each school or department has its own methods of selection and support. Case studies of how the program is implemented and the impact of this on the outcomes for the mentors would be a fruitful area of further examination. Similarly, differences between first time and more experienced mentors have not been examined or separated out in the analysis. The aim was to provide a broad understanding of types of benefits. Given mentors' comments about their own development, in-depth interviews of mentors with different levels of experience would enable a greater understanding of the ongoing role as a mentor and how this contributed to their personal development. Finally, the response rate for the survey was very high as the mentors had to complete this in order to gain their payment. Although this could indicate some coercion, students did not necessarily complete all sections and it was possible to $\log$ in and not provide any responses, and a few students took this option.

\section{Suggestions for future research}

When the mentor program was developed, it was thought that extrinsic rewards of payment and recognition on an academic transcript would be important to attract mentors. Interestingly, only two mentors (females in the Humanities faculty) mentioned the payment in all the responses about benefits. Both had been mentors previously and the payment was reduced after 2009 as more schools undertook the program. One commented that she had enjoyed getting the previously greater amount, and the other said: $I$ received a message from a mentee yesterday saying I was extremely helpful and there should be more people like me! That was worth even more than the upcoming payment! For the mentors in this study, it would appear that intrinsic rewards were more important, but there were no data available regarding the mentors' initial motivations for becoming a mentor and further research could compare initial motivation to engage in mentoring with perceived outcomes.

This study has only focussed on the positive outcomes of the program for mentors. Frustrations or negative outcomes reported by mentors have yet to be analysed. For example, a scan of the data revealed that many mentors were frustrated at the lack of response from their mentees, both in replies to emails as well as in attending face-to-face meetings. Glaser, et al. (2006) found a "significant positive correlation between the proportion of mentees attending the meetings for each mentor and the total self-reported benefits rated by mentors" (p. 13). As the program in the present study was structured differently in different schools, comparing the types of communication (e.g. online or face-to-face, individual or groups) and the related positive and negative perceptions of the mentors (and indeed of the mentees) would be helpful information for program developers.

Haggard et al. (2011) indicated that a fruitful area of research that has received little attention is the motivation of mentors to take on their role and suggested that self-determination theory may provide a useful conceptual framework to understand motivation for mentoring. Selfdetermination theory proposes three basic psychological needs of competence, relatedness and autonomy (Ryan \& Deci, 2000) and the findings of this study indicate the potential relevance of this interpretive framework. In the present 
study for example, mentors reported developing competence in various skills and increased feelings of relatedness or connectedness to their university and the people within it. Autonomy-related benefits were noted when some mentors said they enjoyed the responsibility of their role. It would be interesting to pursue this motivational framework in more depth as a way of conceptualising motivation for mentoring.

\section{Conclusions}

The findings have the potential to be used by the specific program's coordinators to attract mentors as well as to indicate to policy makers and funders that the benefits are broader than just for the first years involved. The study adds to the extant literature indicating that mentoring programs benefit a range of participants in a higher education setting, in addition to the well-documented benefits for first year students. In conclusion, not only does a university-wide co-curricular peer mentoring program have the potential to provide a range of positive outcomes for commencing university students, but also such programs provide positive outcomes for the mentors involved.

\section{Acknowledgements}

The authors thank Dr Jim Elliott and Ms Ebonee Lynch for their assistance in providing the data for this study and providing feedback on the interpretations offered in the paper.

\section{References}

Australian Government. (2008). Review of Australian higher education: Final report. Retrieved from

www.deewr.gov.au/he review finalreport.

Australian Government. (2009). Transforming Australia's higher education system. Retrieved from http://www.deewr.gov.au/HigherEducatio n/Documents/PDF/Additional\%20Report $\% 20-$

\%20Transforming\%20Aus $\% 20$ Higher $\% 20$ ED webaw.pdf

Calder, A. (2004). Peer interaction in the transition process. Journal of the Australia and New Zealand Student Services Association, 23, 416. Retrieved from http://www.adcet.edu.au/anzssa/View.asp $\underline{x}$ id $=7436$

Curtin University. (2011a). Outline of the Mentor Program. Retrieved from http://mentoring.curtin.edu.au/staff/

Curtin University. (2011b). Recruitment. Retrieved from

http://mentoring.curtin.edu.au/staff/recru itment.cfm\#coordstaff

Curtin University. (2011c). 2011 Mentor Training. Retrieved from http://mentoring.curtin.edu.au/mentors/tr aining.cfm

Curtin University. (2011d). Mentor FAQs. Retrieved from http://mentoring.curtin.edu.au/faqs/

Dearlove, J., Farrell, H., Handa, N., \& Pastore, C. (2007). The evolution of peer mentoring at the University of Western Sydney. Journal of the Australia and New Zealand Student Services Association, 29, 21-35.

Devereux, L. (2004, July). When Harry met Sarita: Using a peer-mentoring program to develop intercultural wisdom in students. Paper presented at the Higher Education Research and Development Society of Australasia Conference, Miri, Curtin University, Sarawak Campus, Malaysia.

Dondero, G. (1997). Mentors: Beacons of hope. Adolescence, 32(128), 881-886.

Drew, N., Pike, L., Pooley, J., Young, A., \& Breen, L. (2000, July). School of Psychology Peer Mentoring Pilot Programme. Paper presented at the The Fourth Pacific Rim First Year in Higher Education Conference: Creating Futures for a New Millennium, Brisbane, Australia. Retrieved from http://www.fyhe.com.au/past papers/abst racts/PooleyAbstract.htm 
Ehrich, L., Hansford, B., \& Tennent, L. (2004). Formal mentoring programs in education and other professions: A review of the literature. Educational Administration Quarterly, 40(4), 518-540. doi:10.1177/0013161X04267118. Retrieved from: http://eaq.sagepub.com/content/40/4/51 8.

Elliott, J., Beltman, S., \& Lynch, E. (2011, June-July). "If you make a difference, you have changed someone's life": Outcomes from a university student mentor program. Paper presented at the First Year in Higher Education Conference, Fremantle, Australia.

Fox, A., Stevenson, L., Connelly, P., Duff, A., \& Dunlop, A. (2010). Peer-mentoring undergraduate accounting students: The influence on approaches to learning and academic performance. Active Learning in Higher Education, 11(2), 145-156. doi: $10.1177 / 1469787410365650$.

Gilles, C., \& Wilson, J. (2004). Receiving as well as giving: Mentors' perceptions of their professional development in one teacher induction program. Mentoring \&Tutoring, 12(1), 87-106.

Glaser, N., Hall, R., \& Halperin, S. (2006). Students supporting students: The effects of peer mentoring on the experiences of first year university students. Journal of the Australia and New Zealand Student Services Association, 27, 4-17. Retrieved from http://www.adcet.edu.au/anzssa/View.asp $\underline{x}$ id $=7434$

Haggard, D., Dougherty, T., Turban, D., \& Wilbanks, J. (2011). Who is a mentor? A review of evolving definitions and implications for research. Journal of Management, 37(1), 280-304.

doi:

$10.1177 / 0149206310386227$

Hayes, A. (2005). An SPSS procedure for computing Krippendorff's alpha. Retrieved from: http://www.comm.ohiostate.edu/ahayes/macros.htm

Hayes, A., \& Krippendorff, K. (2007). Answering the call for a standard reliability measure for coding data. Communication Methods and Measures, 1(1), 77-89. doi: $10.1080 / 19312450709336664$

Heirdsfield, A., Walker, S., Walsh, K., \& Wilss, L. (2008). Peer mentoring for first-year teacher education students: The mentors.
Mentoring \& Tutoring, 16(2), 109-124. doi: $10.1080 / 13611260801916135$

Hughes, C., Boyd, E., \& Dykstra, S. (2010). Evaluation of a university-based mentoring program: Mentors' perspectives on a service-learning experience. Mentoring \& Tutoring, 18(4), 361-382. doi:10.1080/13611267.2010.511844

MacCallum, J., \& Beltman, S. (2003). Bridges and barriers in Australia's youth mentoring programs. In F. Kochan \& J. Pascarelli (Eds.), Reconstructing context, community and culture through mentoring: Global perspectives (pp. 73-103). Greenwich, CT: Information Age Publishing.

Morosanu, L., Handley, K., \& O'Donovan, B. (2010). Seeking support: Researching first-year students' experiences of coping with academic life. Higher Education Research \& Development, 29(6), 665-678. doi: 10.1080/07294360.2010.487200

Ryan, R., \& Deci, E. (2000). Intrinsic and extrinsic motivations: Classic definitions and new directions. Contemporary Educational Psychology, 25(1), 54-67. doi: 10.1006/ceps.1999.1020

Shrestha, C., May, S., Edirisingha, P., Burke, L., \& Linsey, T. (2009). From face-to-face to ementoring: Does the "e" add any value for mentors? International Journal of Teaching and Learning in Higher Education, 20(2), 116-124.

Terrion, J., \& Leonard, D. (2007). A taxonomy of the characteristics of student peer mentors in higher education: Findings from a literature review. Mentoring \& Tutoring, 15(2), 149 164. doi: $10.1080 / 13611260601086311$

Terrion, J., Philion, R., \& Leonard, D. (2007). An evaluation of a university peer-mentoring training programme. International Journal of Evidence Based Coaching and Mentoring, 5(1), 42-57. 